ARTICLE

DOI: $10.1038 / \mathrm{s} 41467-018-07236-4$

\title{
Unmasking GluN1/GluN3A excitatory glycine NMDA receptors
}

\author{
Teddy Grand', Sarah Abi Gerges², Mélissa David', Marco A. Diana² \& Pierre Paoletti ${ }^{1}$
}

GluN3A and GluN3B are glycine-binding subunits belonging to the NMDA receptor (NMDAR) family that can assemble with the GluN1 subunit to form unconventional receptors activated by glycine alone. Functional characterization of GluN1/GluN3 NMDARs has been difficult. Here, we uncover two modalities that have transformative properties on GluN1/ GluN3A receptors. First, we identify a compound, CGP-78608, which greatly enhances GluN1/GluN3A responses, converting small and rapidly desensitizing currents into large and stable responses. Second, we show that an endogenous GluN3A disulfide bond endows GluN1/GluN3A receptors with distinct redox modulation, profoundly affecting agonist sensitivity and gating kinetics. Under reducing conditions, ambient glycine is sufficient to generate tonic receptor activation. Finally, using CGP-78608 on P8-P12 mouse hippocampal slices, we demonstrate that excitatory glycine GluN1/GluN3A NMDARs are functionally expressed in native neurons, at least in the juvenile brain. Our work opens new perspectives on the exploration of excitatory glycine receptors in brain function and development.

\footnotetext{
${ }^{1}$ Institut de Biologie de l'Ecole Normale Supérieure (IBENS), Ecole Normale Supérieure, Université PSL, CNRS, INSERM, F-75005 Paris, France. ${ }^{2}$ Institut de Biologie Paris-Seine (IBPS) Sorbonne Université, CNRS, INSERM, Neurosciences Paris-Seine (NPS), UPMC Université Paris 06, F-75005 Paris, France. These authors contributed equally: Teddy Grand, Sarah Abi Gerges. These authors jointly supervised this work: Marco A. Diana, Pierre Paoletti. Correspondence and requests for materials should be addressed to M.A.D. (email: marco.diana@upmc.fr) or to P.P. (email: pierre.paoletti@ens.fr)
} 
$\mathrm{N}$ MDARs are tetrameric ligand-gated ion channels that serve critical roles in CNS development and function. Normal NMDAR activity is essential for neuronal plasticity and information storage, while NMDAR dysfunction contributes to various CNS disorders including epilepsy, mental retardation, and schizophrenia ${ }^{1-3}$. Conventional NMDARs composed of two GluN1 and two GluN2 subunits require two agonists, glutamate and glycine (or D-serine), for activation ${ }^{4}$. They are highly permeable to $\mathrm{Ca}^{2+}$, exhibit strong voltage-dependency due to $\mathrm{Mg}^{2+}$ pore block, and cluster at excitatory synapses where they control synaptic strength by acting as coincidence detectors ${ }^{5}$. The functional diversity and signaling properties of GluN1/GluN2 NMDARs have been extensively characterized during the last 30 years, providing a wealth of information on the molecular basis of excitatory neurotransmission.

Much less is known regarding NMDARs incorporating the two glycine-binding subunits GluN3A and GluN3B, cloned in 1995 and 2001, respectively ${ }^{6-10}$. The general architecture of GluN3 subunits is globally similar to that of GluN1-2 subunits, yet the two families differ by the conspicuous presence of a positive charge in the pore-lining sequence of GluN3, and by the unique structural determinants of the GluN3 glycine-binding site $^{11,12}$. GluN3A and GluN3B subunits also display differential ontogenic profiles. GluN3A is widely expressed in the CNS during early postnatal life and participates in synapse maturation $^{13-15}$, before progressively declining in abundance ${ }^{16}$. Conversely, GluN3B expression slowly increases throughout development, albeit remaining restricted to defined CNS regions (e.g. motoneurones ${ }^{10,17}$ ). GluN3-containing NMDARs are either glutamate/glycine-activated triheteromeric receptors composed of GluN1, GluN2, and GluN3 subunits or glycine-activated diheteromeric receptors composed of GluN1 and GluN3 subunits ${ }^{18-}$ 20 . Both assemblies form cationic channels with strongly reduced $\mathrm{Ca}^{2+}$ permeability and $\mathrm{Mg}^{2+}$-block compared to GluN1/GluN2 receptors. Surprisingly, while the GluN3 subunit appears to act as a dominant negative regulator in triheteromeric GluN1/ GluN2/GluN3 receptors ${ }^{21,22}$, in GluN1/GluN3 diheteromers, the GluN3 subunit has a primary role in receptor activation $10,23,24$.

Unconventional glycine-activated GluN1/GluN3 NMDARs have sparked intense curiosity and controversy. First, they constitute a new type of glycine excitatory receptor, since glycine is well established as an inhibitory neurotransmitter in the spinal cord and brainstem ${ }^{25-27}$. Second, they have so far been mostly described in recombinant systems with only sparse evidence for their existence in vivo ${ }^{28}$. Glycine currents produced by unconventional GluN1/GluN3 receptors are small, unstable and difficult to quantify $10,23,24,29-31$, complicating the study of these receptors. Third, GluN1/GluN3 receptor pharmacology is meager. Antagonists with good potency and selectivity are missing, while available potentiators do not alter the transient nature of GluN1/GluN3 responses and usually produce complex biphasic effects $^{23,24,32-34}$. In this study, we show that the quinoxalinedione CGP-78608, known to antagonize GluN1/GluN2 receptors ${ }^{35}$, acts as an ultra-potent and powerful potentiator of GluN1/GluN3A receptors. The effects produced are unprecedented in their extent with potentiation factors much greater than previously observed with other GluN1-binding molecules. Building on this discovery, we also show that GluN1/GluN3A receptors can alternate between two modes of agonist sensitivity in a redox-dependent manner. In the high-affinity mode, ambient glycine is sufficient to tonically activate the receptors. Lastly, capitalizing on the discovery of the CGP-78608 as a massive enhancer of GluN1/ GluN3A receptors, we identify excitatory glycine GluN1/GluN3A receptors as a new type of neuronal receptors, being functionally expressed in the juvenile brain. This work has broad ranging implications for the study of GluN1/GluN3A receptors and of glycine as an excitatory neurotransmitter.

\section{Results}

CGP-78608 awakens GluN1/GluN3A receptors. Diheteromeric GluN1/GluN3 receptors display peculiar activation properties with no equivalent in the NMDAR family. In particular, contrasting with GluN1/GluN2 complexes, glutamate is dispensable for their activation ${ }^{10}$. Moreover, while glycine binding to GluN3 subunits triggers channel opening, glycine binding to the neighboring GluN1 subunits has an opposite effect causing autoinhibition by rapid entry into a non-conducting desensitized state. Accordingly, receptors carrying single-point mutations that prevent glycine binding to GluN1 show large and nondesensitizing glycine-activated currents ${ }^{23,24,30,33}$. Taking advantage of these unique gating properties, we sought to find a small molecule compound able to antagonize glycine binding to GluN1 but not to GluN3A. Several GluN1-preferring ligands have already been shown to potentiate GluN1/GluN3 currents ${ }^{23,24}$, yet none achieves high level of potentiation together with current stability during prolonged agonist application. Our attention focused on CGP-78608, a NMDAR GluN1 competitive antagonist $^{35}$ which, according to radiolabeled binding studies on isolated agonist-binding domains (ABDs), displays a thousand-fold selectivity for GluN1 vs GluN3 ${ }^{11}$. We expressed diheteromeric GluN1/GluN3A receptors in HEK293 cells and studied their activity using whole-cell patch-clamp recordings coupled to a fast perfusion system. Application of glycine alone $(100 \mu \mathrm{M})$ elicited very small (few tens of $\mathrm{pA}$ ) and rapidly desensitizing currents (Fig. 1a), as previously described ${ }^{30,31,34}$. Pre-application of CGP78608 (500 nM) dramatically enhanced the glycine-induced currents, which reached several $\mathrm{nA}$ in amplitude, and greatly reduced desensitization (Fig. 1a). Overall, peak and steady-state currents were potentiated $128 \pm 24$ fold (range $50-296 ; n=11$ ), and $335 \pm$ 266 fold (range 106-876; $n=11$ ), respectively (Fig. 1a). Concomitantly, the extent of desensitization was strongly decreased $\left(I_{\text {ss }} / I_{\text {peak }}\right.$ increased from $0.30 \pm 0.03[n=8]$ to $0.80 \pm 0.03[n=5]$; $P<0.001$, Student's $t$-test) and desensitization kinetics slowed considerably $\left(\tau_{\text {des }}\right.$ increased from $81 \pm 13 \mathrm{~ms}[n=8]$ to $1642 \pm$ $183 \mathrm{~ms}[n=5] ; P<0.001$, Student's $t$-test). A full dose-response curve (Fig. 1b) revealed that CGP-78608 was extremely potent as a potentiator of GluN1/GluN3A-mediated glycine currents, with an estimated $\mathrm{EC}_{50}$ in the low $\mathrm{nM}$ range $(26.3 \pm 5.0 \mathrm{nM}[n=$ 4-11]; measured at peak current), closely matching the value found on the isolated GluN1 ABD (6.4 nM; ref. $\left.{ }^{11}\right)$. In line with a classical bimolecular drug-receptor interaction, the effects of CGP-78608 were fully reversible (Supplementary Figure 1a). Furthermore, introduction of the GluN1-F484A mutation to prevent ligand binding to the GluN1 subunit ${ }^{23,24}$ almost completely abolished the potentiating effects of CGP-78608 (Fig. 1d and Supplementary Figure 1b), consistent with CGP-78608 binding to GluN1 ABDs of GluN1/GluN3 receptors as it does on conventional GluN1/GluN2 receptors. Unsurprisingly, the amplitudes of glycine-triggered currents carried by GluN1F484A/GluN3A receptors were much larger than those of wildtype GluN1/GluN3A receptors (Supplementary Figure 1b), confirming the inhibitory role on receptor activation of glycine binding to GluN1.

We obtained further evidence that CGP-78608 produces uniquely large potentiating effects on GluN1/GluN3A receptors by systematic comparison with other GluN1 competitive antagonists previously tested on these receptors ${ }^{23,24,30:}$ MDL29951, the kynurenic acid derivative 7-CKA, and L-689560. Similar to previous experiments, GluN1 competitive antagonists were first pre-incubated before triggering receptor activation by 
a

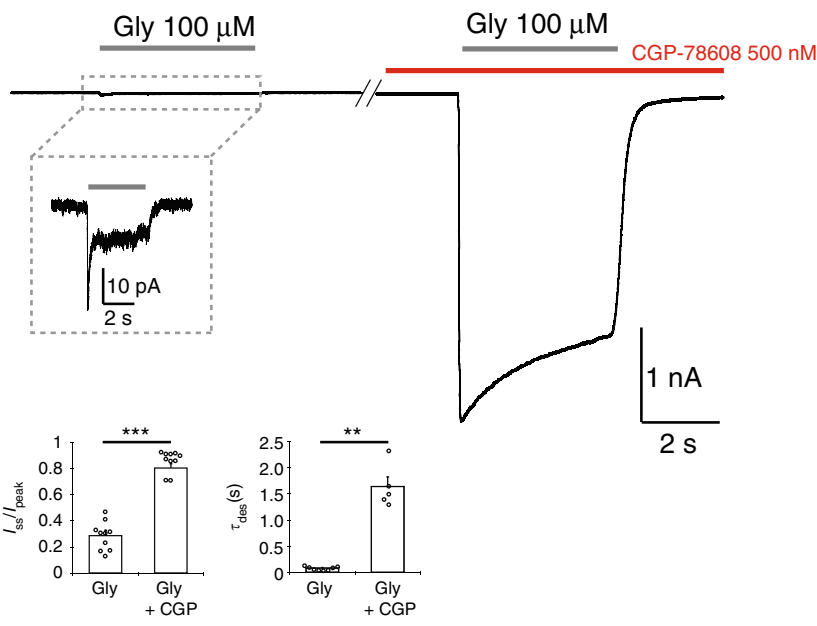

b

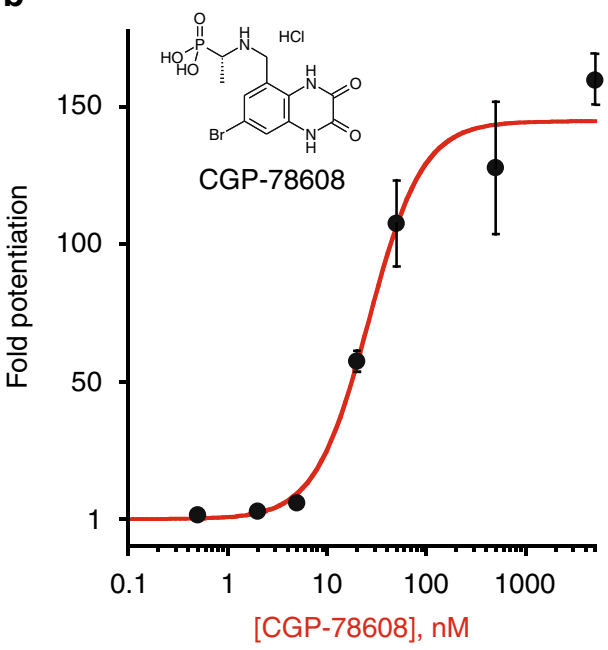

c
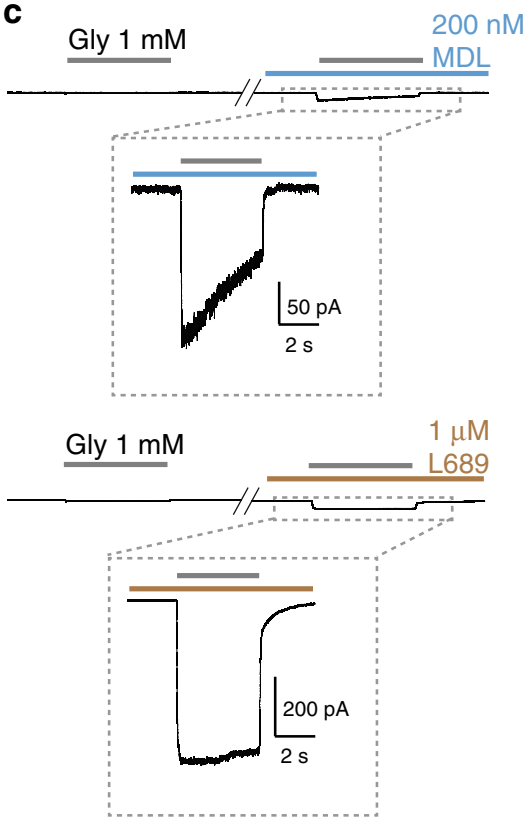

$10 \mu \mathrm{M}$
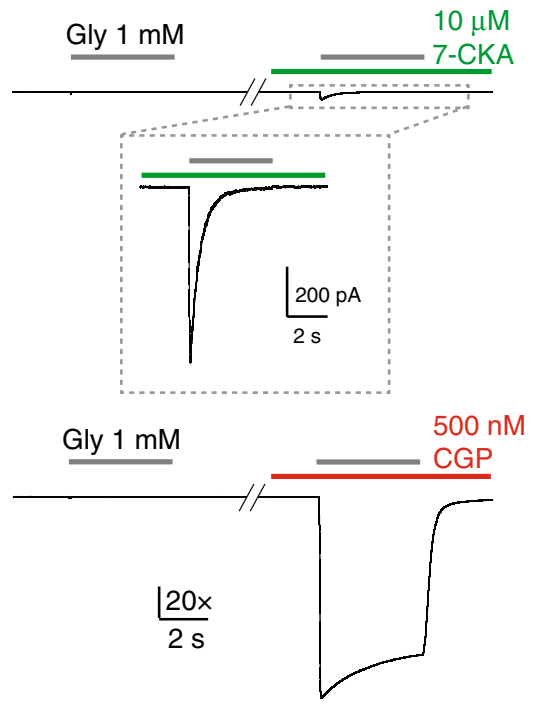

d

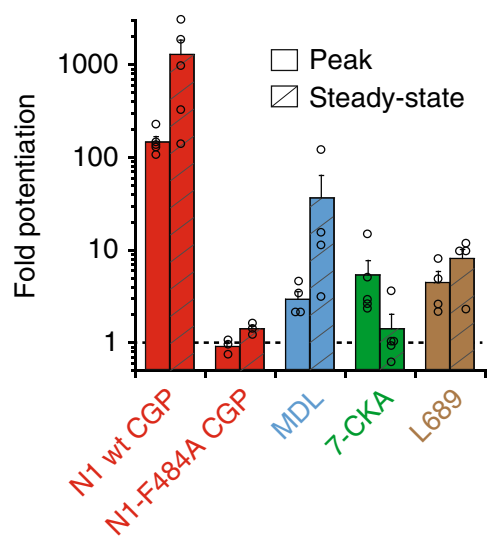

Fig. 1 The GluN1 antagonist CGP-78608 awakes GluN1/GluN3A receptors. a Pre-application of CGP-78608 massively potentiates excitatory glycine GluN1/GluN3A receptor responses. Bar graphs indicate effect on extent $\left(I_{\mathrm{ss}} / I_{\text {peak }}\right)$ and kinetics $\left(\tau_{\text {des }}\right)$ of desensitization. ${ }^{\star \star \star} P<0.001$, Student's $t$-test, $(n=10) ;{ }^{\star \star} P=0.002$, Mann-Whitney test $(n=10)$. b CGP-78608 potentiation dose-response curve obtained in presence of $100 \mu \mathrm{M}$ glycine. Currents were measured at the peak. $\mathrm{EC}_{50}=26.3 \pm 5 \mathrm{nM}, n_{\mathrm{H}}=1.45(n=4-11)$. c Representative current traces showing the relative potentiation of various GluN1 antagonists compared to CGP-78608. Traces are normalized to the glycine-induced peak currents obtained prior to drug application. $\mathbf{d}$ Quantification of effects of GluN1 antagonists tested in c on peak and steady-state current levels $(n=4-6)$. N1-F484A refers to the GluN1-F484A mutant subunit. All recordings were performed in HEK293 cells. Data are mean \pm SEM

applying additional glycine $(1 \mathrm{mM})$. The concentration of each compound was set above its reported GluN1 binding affinity (Ki; see Methods) to insure sufficient binding site occupancy. As illustrated in Fig. 1c, all three compounds potentiated GluN1/ GluN3A receptors, yet their effects were singularly less prominent than those produced by CGP-78608. Thus, while CGP-78608 $(500 \mathrm{nM})$ potentiated peak and steady-state currents by $>100$-fold $(n=5)$ and $>1000$-fold $(n=5)$, respectively, corresponding values were orders of magnitude lower for MDL-29951, 7-CKA, and L-689560 (Fig. 1d). Strikingly, for these three latter compounds, the magnitude of potentiation and the impact on the shape of the glycine currents differed significantly. 7-CKA produced the largest peak potentiation but desensitization remained profound with little current remaining at steady-state. In contrast, MDL-29951, and to a lesser extent L-689560, greatly enhanced steady-state currents such that glycine responses were measurable during long agonist applications. These different patterns likely relate to the complex interplay between glycine and compound molecules for binding GluN1 and GluN3A subunits (see Discussion). Importantly, though, none of these three drugs produced effects comparable to CGP-78608, considering both the extent of peak and steady-state current potentiation. In agreement with its very high potency (i.e. low $\mathrm{EC}_{50}$ ), washout experiments revealed slow offset kinetics of CGP78608 from GluN1/GluN3A receptors, with dissociation time constants in the tens of seconds time scale (both from the active or resting state of the receptor; $\tau_{\text {off }}$ of $27.6 \pm 6.3 \mathrm{~s}[n=6]$ and 22.5 $\pm 4.2 \mathrm{~s}[n=4]$, respectively; Fig. $2 \mathrm{a}$ ). By inverting the order of application between CGP-78608 and glycine, we also found the CGP-78608 potentiation to be strongly state-dependent. Indeed, 
a

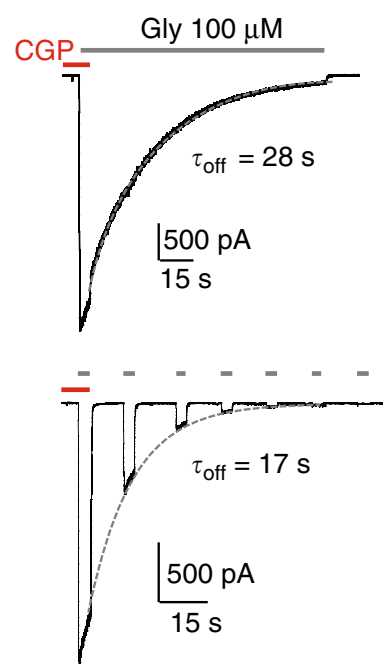

b
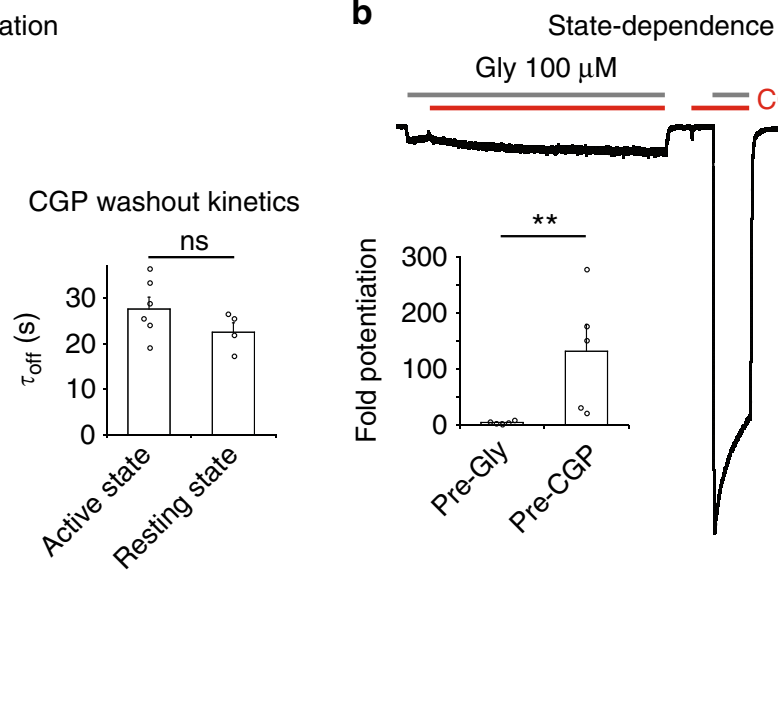

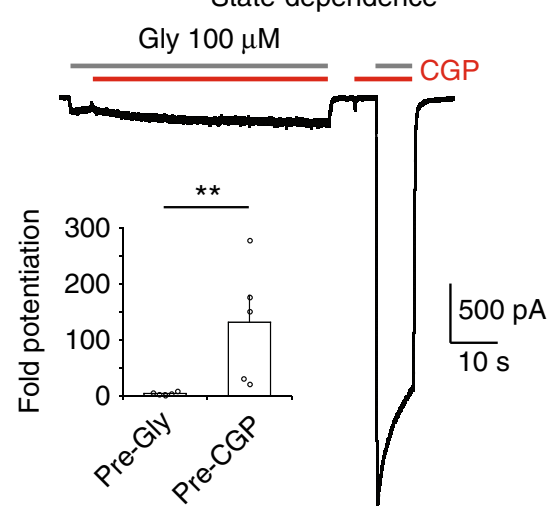

Fig. 2 Kinetics and activity-dependence of CGP-78608 potentiation at GluN1/GluN3A receptors. a CGP-78608 washout kinetics in the presence of continuous or pulses of glycine. CGP-78608 was applied at $500 \mathrm{nM}$. Bar graph: comparison of the CGP-78608 washout kinetics in the active (upper trace) or resting state (lower trace). n.s. $P=0.198$, Student's $t$-test; $(n=4-6)$. b CGP-78608 potentiation is state-dependent. Potentiation by CGP-78608 (500 $\mathrm{nM}$ ) is greatly reduced when the compound is applied after, rather than before, application of glycine (pre-Gly vs post-Gly, respectively). Bar graph: potentiation measured at steady-state. ${ }^{\star \star} P=0.008$, Mann-Whitney test, $(n=5)$. Data are mean \pm SEM

only minimal potentiation was observed on receptors preoccupied with glycine, while CGP-78608 application before glycine still induced massive effects on the very same receptor population (Fig. 2b). This pre vs post pattern likely finds its origin in the relative affinities of GluN1 and GluN3 ABDs for glycine and CGP-78608 while the receptor transits along the activation pathway (from resting, to active and desensitized states; see Discussion). Using CGP-78608, we also confirmed that D-serine (up to $500 \mu \mathrm{M}$ ) triggered currents of smaller amplitude than those elicited by glycine $(100 \mu \mathrm{M})$ (Supplementary Figure 1c), in agreement with $\mathrm{D}$-serine having lower efficacy than glycine at GluN1/GluN3A receptors. Finally, we found all salient effects of CGP-78608 (current potentiation, reduction of desensitization, state-dependence) described in HEK293 cells to be conserved in Xenopus oocytes, highlighting the robustness of the CGP-78608 effects regardless of the expression system. In many oocytes, application of CGP-78608 unveiled massive glycine-induced currents (several $\mu \mathrm{A}$ ), while prior applications of glycine alone on the very same cells virtually produced no detectable currents (Supplementary Figure 1d,e). These results provide additional proof that the compound CGP-78608 is unprecedented in its effects on excitatory glycine GluN1/GluN3A NMDARs. They also reveal that GluN1/GluN3A receptors, despite the small currents recorded when applying glycine only, express at very high levels in heterologous expression systems.

To better assess the activation parameters of GluN1/GluN3A receptors, we next performed glycine concentration-response curves in the presence or absence of CGP-78608. In control conditions, GluN1/GluN3A receptors displayed low $\mu \mathrm{M}$ glycine sensitivity $\quad\left(\mathrm{EC}_{50}=7.1 \pm 0.4 \mu \mathrm{M} \quad[n=5-15]\right.$, peak responses; Supplementary Figure 2a), in agreement with previous estimates $^{23,24}$. In the presence of CGP-78608 (500 nM), in conditions where current responses are several orders of magnitude larger, glycine sensitivity was moderately decreased $\left(\mathrm{EC}_{50}=39 \pm 0.8 \mu \mathrm{M}[n=6]\right.$; Supplementary Figure $\left.2 \mathrm{~b}\right)$. This $\sim 5$ fold rightward shift in agonist sensitivity may be due either to a direct competition between glycine and CGP-78608 binding to GluN3A ABD sites, or to an indirect (i.e. allosteric) effect of CGP78608 binding at GluN1 ABD sites onto GluN3A ABD glycine sites. To distinguish between these two possibilities, we repeated the concentration-response curve experiment with a 10-fold lower CGP-78608 concentration (50 nM). Under such condition, glycine $\mathrm{EC}_{50}(40 \pm 0.8 \mu \mathrm{M} ;[n=9])$ is almost identical to that measured with $500 \mathrm{nM}$ CGP-78608 (Supplementary Figure 2c). This result strongly suggests that CGP-78608 decreases glycine sensitivity of GluN1/GluN3A receptors through an inter-subunit allosteric effect between GluN1 and GluN3A ABD sites.

Redox treatment transforms GluN1/GluN3A receptor properties. Conventional GluN1/GluN2 NMDARs display a wellcharacterized redox sensitivity mediated by two critical GluN1 cysteine residues (C744 and C798) forming a disulfide bond, which increases the magnitude of NMDAR-evoked responses when chemically reduced ${ }^{36-38}$. Redox modulation is thought to provide an important regulatory mechanism of NMDAR signaling during normal and diseased brain function ${ }^{39-43}$. Because the redox sensitivity of GluN1/GluN3 receptors remains uncharacterized, we decided to investigate the effects of reducing treatments on glycine responses mediated by GluN1/GluN3A receptors. Recordings from HEK293 cells treated with the reducing agent TCEP ( $5 \mathrm{mM}, 20 \mathrm{~min})$ revealed drastic effects on GluN1/GluN3A glycine-evoked responses (Fig. 3b, c). The most conspicuous effect concerned the shape of the responses. First, when glycine was applied, peak currents from reduced GluN1/ GluN3A receptors desensitized to a steady-state current that was more positive than the baseline holding current. Second, upon washout of glycine, very large and slowly decaying tail (or rebound) currents appeared. The size of the peak current induced by glycine application was also greatly increased following TCEP treatment. With the aim of identifying the molecular determinants underlying these effects, we first recorded from GluN1/ GluN3A receptors lacking the endogenous GluN1 disulfide bridge responsible for the redox sensitivity of conventional GluN1/ GluN2 NMDARs. Despite enhanced current amplitude prior to TCEP treatment, GluN1-C744S-C798S/GluN3A receptor currents remained remarkably sensitive to reduction, displaying the striking shape transformation observed on wild-type GluN1/ 
a
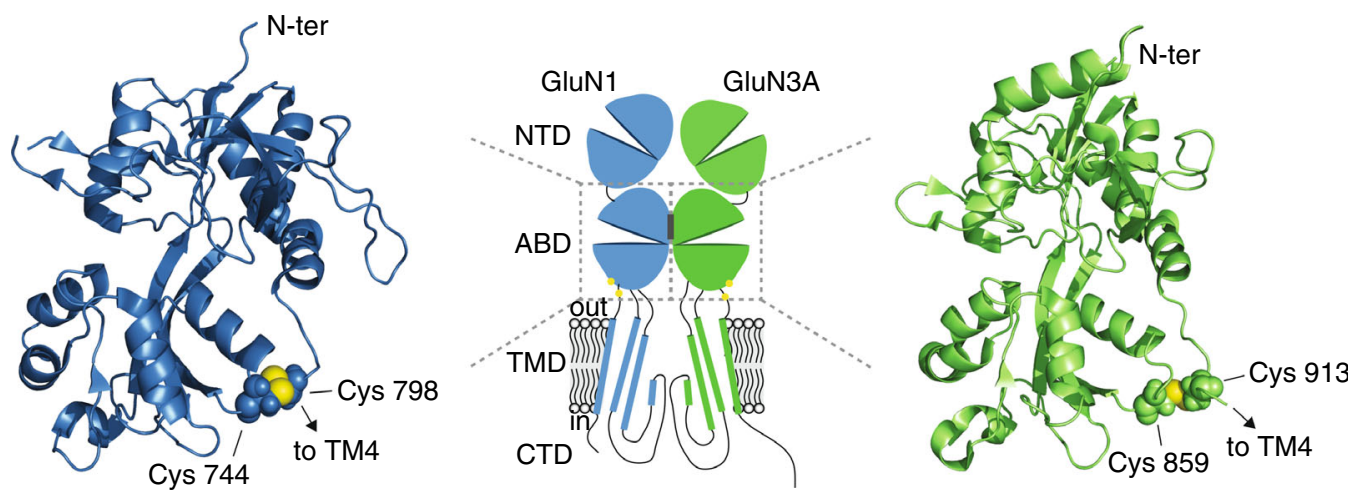

b

HEK cells

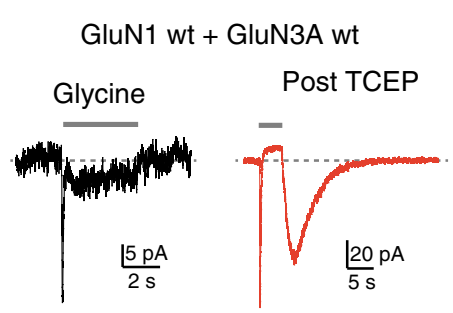

GluN1 wt + GluN3A-CS-CS
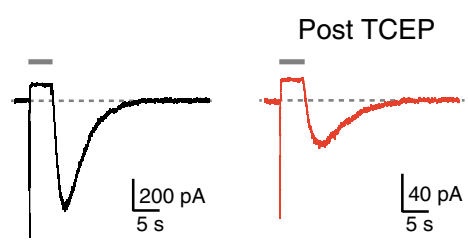

d

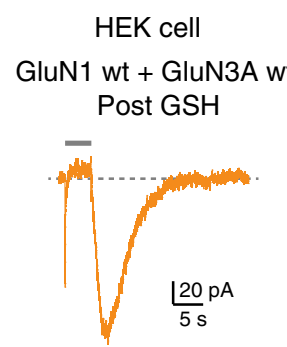

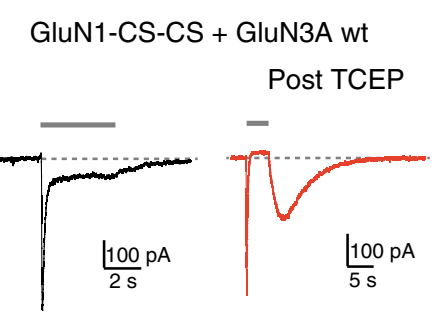

GluN1-CS-CS + GluN3A-CS-CS

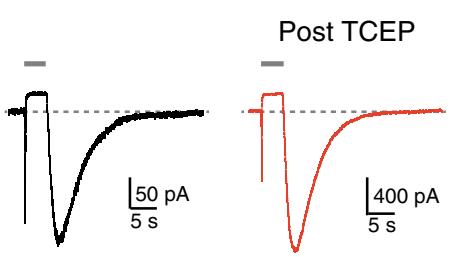

e

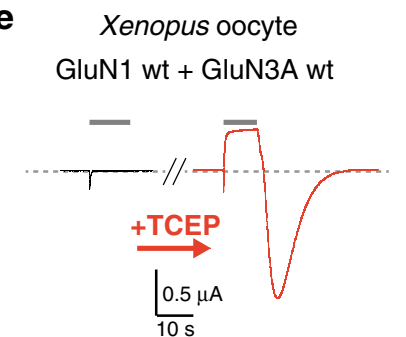

C
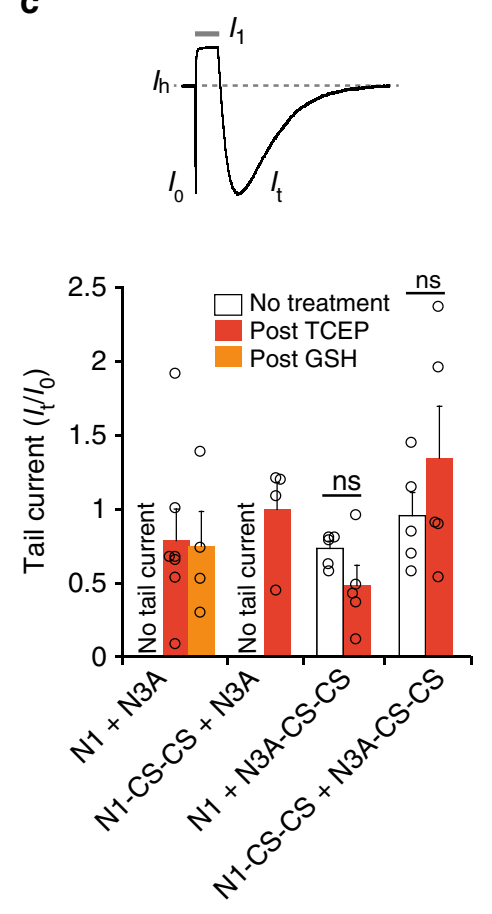

Fig. 3 GluN1/GluN3A receptors display strong redox sensitivity. a Structure of the GluN1 and GluN3A ABDs (PDB 4KCC and 4KCD, respectively55). Cysteines involved in endogenous redox-sensitive disulfide bridges are highlighted (sulfur atoms shown in yellow). The central cartoon illustrates domain organization in GluN1/GluN3A receptors; NTD, N-terminal domain; ABD, agonist-binding domain; TMD, transmembrane domain; CTD, C-terminal domain. b Effect of TCEP treatment ( $5 \mathrm{mM}, 20 \mathrm{~min}$ ) on wild-type and mutant GluN1/GluN3A receptors expressed in HEK 293 cells. Glycine was applied at $100 \mu \mathrm{M}$. Each trace comes from a separate cell. c Quantification of tail currents observed upon washout of glycine on wild-type and mutant GluN1/GluN3A receptors. Inset indicates current tags used for quantification. n.s. $P=0.125$ and 0.337 , Student's $t$-test $(n=4-9)$. Note that non-treated receptors containing wild-type GluN3A subunits do not exhibit tail currents. Data are mean \pm SEM. d Effect of reduced glutathione (GSH, $50 \mathrm{mM}$ for $20 \mathrm{~min}$ ) on wildtype GluN1/GluN3A receptors expressed in HEK293 cells. Glycine was applied at $100 \mu \mathrm{M}$. e Effect of TCEP treatment (5 mM, $20 \mathrm{~min}$ ) on wild-type GluN1/ GluN3A receptors expressed in Xenopus oocytes. The pair of current traces corresponds to responses before and after TCEP treatment on the same cell. Glycine was applied at $100 \mu \mathrm{M}$

GluN3A receptors (Fig. 3b, c). A critical component of the redox sensitivity of GluN1/GluN3A receptors is therefore independent of the endogenous GluN1-C744-C798 disulfide bridge. Because a homologous disulfide bridge involving C859 and C913 is present in GluN3 $\mathrm{A}^{11}$ (Fig. 3a), we next recorded from mutant GluN1/ GluN3A-C859S-C913S receptors. Distinct features emerged (Fig. 3b, c): first, the TCEP sensitivity (on current shape) was lost; second, the current responses in basal conditions (i.e. prior to TCEP treatment) were remarkably similar in shape to those of reduced currents from wild-type receptors. Similar effects absence of TCEP sensitivity, current shape transformation - were also present on receptors with the disulfide bonds mutated on both subunits (GluN1-C744S-C798S/GluN3A-C859S-C913S; Fig. 3b, c). Finally, we tested the endogenous reducing agent glutathione (GSH) on wild-type GluN1/GluN3A receptors. Similar to TCEP treatment, GSH incubation completely modified the current phenotype, with the appearance of an outward shifted steady-state current and large rebound currents upon removal of 
glycine (Fig. 3c, d). Overall, these results show that GluN1/ GluN3A receptors are highly redox sensitive, with activation properties that can adopt two strikingly different patterns depending on the redox state. They also identify the endogenous GluN3A ABD C859-C913 disulfide bridge as a key molecular determinant of this redox modulation.

We then turned to Xenopus oocytes to better estimate the relative contribution of the GluN1 and GluN3A subunits to the redox sensitivity of GluN1/GluN3A receptors. Indeed, we observed that oocytes better tolerated redox treatment than HEK293 cells, thus allowing robust comparison of currents from the same cell before and after reduction. When applying the reducing agent TCEP to wild-type GluN1/GluN3A receptors, currents radically changed, reproducing faithfully the effects previously observed on HEK293 cells. In particular, reduced receptors exhibited massive rebound currents upon washout of glycine, with much larger peak amplitudes than before TCEP treatment, and slow deactivation kinetics requiring tens of seconds for full recovery (Fig. 3e). Similar effects were observed when using the reducing agent DTE instead of TCEP (Supplementary Figure $3 \mathrm{a}, \mathrm{b}$ ). In addition, following the initial peak current triggered by glycine application, currents stabilized to a steady-state level lower (i.e. reduced inward current) than that measured prior to glycine application (Fig. $3 \mathrm{e}$ and see below). Having confirmed the reproducibility of the redox effects in both expression systems, we next aimed at deciphering the specific contribution of each subunit to the redox modulation of GluN1/ GluN3A receptors. For that purpose, we assessed the redox sensitivity of receptors expressed in oocytes and lacking either the GluN1-C744-C798 disulfide bridge, or the GluN3A-C859-C913 disulfide bridge, or both. Comparison of mutant receptors revealed a clear dichotomy (Supplementary Figure 3a, b), where the GluN1 disulfide bridge controls current amplitude yet has little effect on the current shape, while the GluN3 disulfide bridge is responsible for the radical change in both current shape and time course.

Tonic activation of reduced GluN1/GluN3A receptors. Given the opposing effects of GluN1 and GluN3A subunits on GluN1/ GluN3A receptor activation ${ }^{23,24}$, we hypothesized that breaking the GluN3A-C859S-C913S disulfide bond shifts GluN3A glycine sensitivity, but not that of GluN1, to much higher affinity. Rebound currents upon glycine washout would then occur following fast dissociation of glycine from (inhibitory) GluN1 sites while (activating) GluN3 sites are still occupied. We obtained direct evidence that glycine dissociation kinetics are greatly slowed following GluN3A disulfide bond disruption by performing off-relaxation experiments on CGP-78608-bound non-desensitizing receptors. In such conditions, relaxation kinetics following glycine removal were readily observable and quantified (Fig. 4a, b). Comparison of wild-type and mutant receptors revealed that glycine off-relaxations $\left(\tau_{\text {off }}\right)$ were only weakly affected when breaking the GluN1 disulfide bridge (442 \pm $208 \mathrm{~ms}[n=5]$ for GluN1-C744-C798/GluN3A receptors vs 205 $\pm 110 \mathrm{~ms}[n=7]$ for wt receptors, $P=0.027$, Student's $t$-test; Fig. 4b). In contrast, major effects were observed on receptors lacking the GluN3A bridge with glycine deactivation kinetics greatly slowed down $(2217 \pm 91 \mathrm{~ms}[n=4]$ and $2098 \pm 196 \mathrm{~ms}[n$ =5] for GluN1/GluN3A-C859S-C913S and GluN1-C744SC798S/GluN3A-C859S-C913S receptors, respectively; $P<0.001$, Student's $t$-test comparison with wild-type or GluN1-C744-C798/ GluN3A receptors; Fig. 4b). Interestingly, similarly slow time courses were measured for the decay kinetics of rebound currents (Supplementary Figure 3a, b), likely reflecting slow dissociation of glycine from GluN3A (see Discussion). Full glycine concentration-response curves performed in the presence of CGP-78608 confirmed that mutant receptors displayed enhanced agonist sensitivity compared to their wild-type counterparts (13fold decrease in glycine $\mathrm{EC}_{50}$; Supplementary Figure 2d). Taken together, these results show that the endogenous GluN3A-C859C913 disulfide bridge plays a major role in controlling glycine sensitivity of GluN1/GluN3A receptors. It does so by governing the residency time of glycine on its GluN3A ABD binding site.

We hypothesized that another consequence of the greatly enhanced glycine sensitivity of reduced GluN1/GluN3A receptors are outward shifted steady-state currents (see Fig. 3 and Supplementary Figure 3). The observation that agonist-induced steady-state currents are smaller than resting currents (measured prior to agonist application) is very unusual and may originate from combined effects of receptor desensitization and tonic activation. Accordingly, prior to glycine application, a fraction of reduced GluN1/GluN3 receptors would be constitutively activated by ambient glycine (estimated at $40-50 \mathrm{nM}$ in recording solutions ${ }^{44-46}$ ). Following application of high glycine concentrations, more receptors activate, accounting for the fast inward peak current. Subsequently, however, desensitization would take over progressively accumulating all (or the vast majority of) receptors into a long-lasting inactive state, hence accounting for the apparent outward shift in steady-state current level. As illustrated in Fig. 4c, outward current shifts (represented as down bars) were directly and specifically controlled by the redox state of the GluN3A-C859-C913 disulfide bridge, paralleling the effects seen on the rebound currents. To better identify the nature of the constitutive currents recorded in the absence of added glycine, we used CNQX, an antagonist of GluN1/GluN2 NMDARs and AMPA receptors, also known to inhibit GluN1/GluN3A receptors ${ }^{23,28}$. For cells expressing wild-type receptors, CNQX $(50 \mu \mathrm{M})$ barely changed the holding current (outward current displacement of $0.6 \pm 0.06 \mathrm{pA},[n=6]$; Fig. $4 \mathrm{~d}$ ), as expected if the receptors were not tonically active. In contrast, for cells expressing GluN1-CS-CS/GluN3A-CS-CS receptors, CNQX strongly affected the holding current, displacing its amplitude by $22.9 \pm 8.3 \mathrm{pA},[n=7](P=0.032$ compared to WT, Student's $t$-test), thus indicating a significant level of constitutive receptor activation (Fig. 4d). As expected, CNQX also inhibited the large tail currents carried by mutant receptors following glycine removal (Fig. 4e). Altogether, these results indicate that according to their redox state, GluN1/GluN3A receptors can switch mode, with differential glycine sensitivity. A single endogenous disulfide bond, residing in the GluN3A ABD lower lobe (GluN3A-C859C913), controls this functional switch. In receptors with this S-S bond unlocked, glycine concentrations as low as a few tens of nanomolar appear sufficient to permit GluN3A subunit occupation and receptor activation. This ultra-high glycine sensitivity is unprecedented for functional GluN1/GluN3A receptors. However, it echoes surprisingly well the $40.4 \mathrm{nM}$ glycine affinity found by Yao and Mayer ${ }^{11}$ using radiolabeled ligand assay on the isolated GluN3A ABD.

Functional GluN1/GluN3A receptors in the juvenile brain. The existence of functional glycine excitatory GluN1/GluN3A NMDARs has not been demonstrated in native neurons until present. In native conditions, similar to heterologous systems, glycine binding to GluN1 subunits may reduce currents to undetectable levels because of receptor desensitization. Given its properties on recombinant GluN1/GluN3A receptors, we foresaw that CGP-78608 would represent a powerful tool for revealing endogenous currents mediated by glycine excitatory GluN1/ GluN3A receptors in native tissues. The GluN3A subunit is expressed at high levels and almost ubiquitously at early 
a

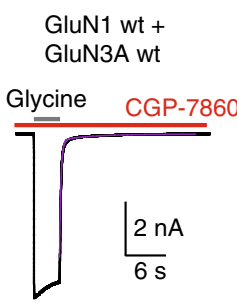

GluN1-CS-CS + GluN3A wt

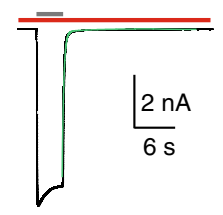

C

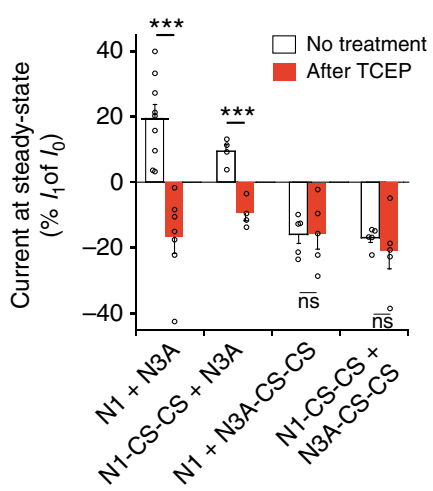

GluN1-CS-CS + GluN3A-CS-CS

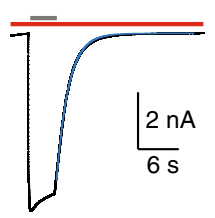

GluN1wt + GluN3A-CS-CS

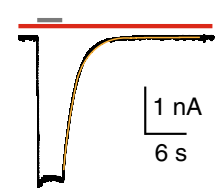

b

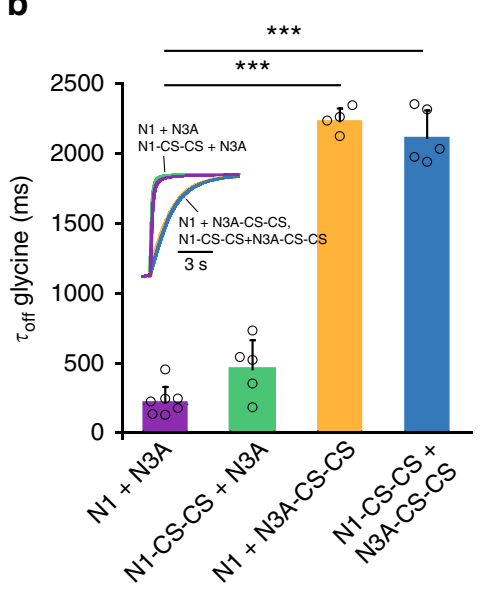

d

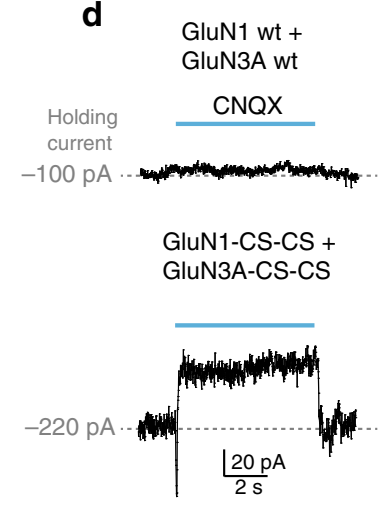

e GluN1-CS-CS + GluN3A-CS-CS

Current inhibition by $50 \mu \mathrm{M}$ CNQX

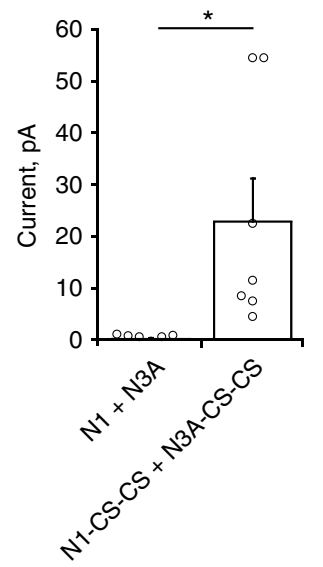

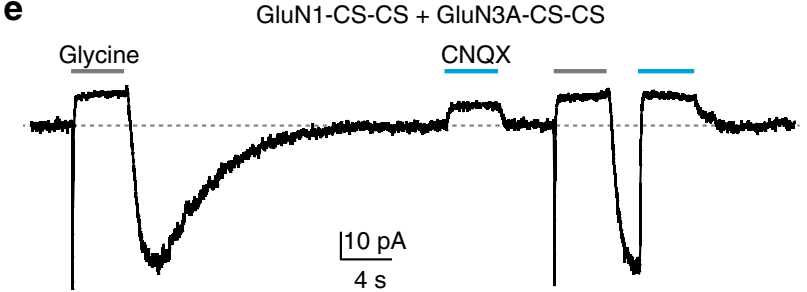

Fig. 4 High-glycine sensitivity and tonic activation of reduced GluN1/GluN3A receptors. a Glycine deactivation kinetics of wild-type and mutant receptors in presence of CGP-78608 $(500 \mathrm{nM})$. Glycine was applied at $100 \mu \mathrm{M}$. b Quantification of glycine deactivation kinetics. ${ }^{\star} P=0.027$, Student's $t$-test; ${ }^{\star \star \star} P<0.001$, Student's $t$-test $(n=4-7)$. Inset: representative current traces and overlaid fits following glycine washout. c Quantification of glycine-induced steady-state outward current shifts following TCEP treatment (see Text). Currents at steady-state $\left(I_{1}\right)$ are expressed as percentage of $I_{0}$ current (see Fig. 2c). ${ }^{\star \star} P<0.001$, Student's $t$-test; n.s. $P=0.95$ and 0.49 , respectively, Student's $t$-test; $(n=4-9)$. d Effect of CNQX (50 $\left.\mu M\right)$ on the holding current (current measured in the absence of glycine) for both wild-type and mutant GluN1-CS-CS/GluN3A-CS-CS receptors. e Effect of CNQX (50 $\mu$ M) on basal and glycine-induced currents carried by GluN1-CS-CS/GluN3A-CS-CS mutant receptors. Note the strong inhibition by CNQX of the tail current (rebound current following glycine removal). Glycine was applied at $100 \mu \mathrm{M}$. All recordings were performed in HEK293 cells. Data are mean \pm SEM

developmental stages ${ }^{16,18,20}$. We thus explored the ex vivo presence of functional GluN1/GluN3A heterodimers in the hippocampal CA1 region of juvenile mouse slices (P8-P12). We examined the effects of bath applications of CGP-78608 on currents activated by glycine $(10 \mathrm{mM})$ puffed onto voltage-clamped CA1 pyramidal cells (Fig. 5a). To avoid potential activation of inhibitory glycine receptors, these experiments were performed in a cocktail of neurotransmitter receptor inhibitors including the inhibitory glycine receptor inhibitor strychnine (see Methods). In control conditions, glycine induced very small inward currents in both wild-type and GluN3A-knock-out ${ }^{13}$ (GluN3A-KO) mice (mean amplitude: $9.3 \pm 1.4 \mathrm{pA}[n=10]$ vs $6.0 \pm 0.8 \mathrm{pA}[n=11]$, respectively; Fig. 5 b, c). Not significantly different $(P=0.3$;
Mann-Whitney test), these currents are likely due, at least in part, to mechanical artefacts triggered by puffing near the recording electrode.

Bath application of CGP-78608 $(1 \mu \mathrm{M})$ produced dramatically different effects in WT and GluN3A-KO mice. In wild-type mice, CGP-78608 massively amplified the glycine-induced inward currents to $190.1 \pm 58.3 \mathrm{pA}(n=10$; range: $16.8-640.6 \mathrm{pA} ; P=$ 0.007 vs control puffs, Wilcoxon signed-rank test), whereas it had no significant effect on currents triggered in GluN3A-lacking animals (mean amplitude of $5.0 \pm 0.6 \mathrm{pA}[n=17] ; P=0.9$ vs control puffs in GluN3A-KO animals; $P=0.00001$ with respect to currents obtained in the presence of CGP-78608 in WT mice; Mann-Whitney test; Fig. 5b, c). Finally, in wild-type mice bath 
a

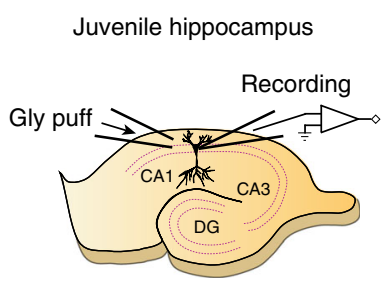

b

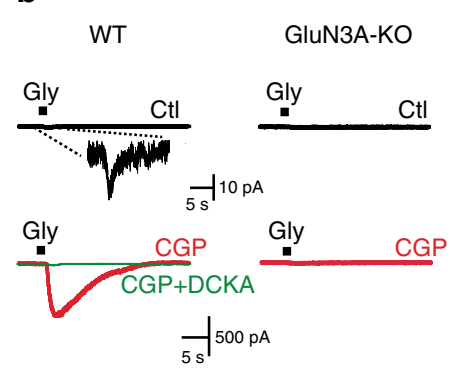

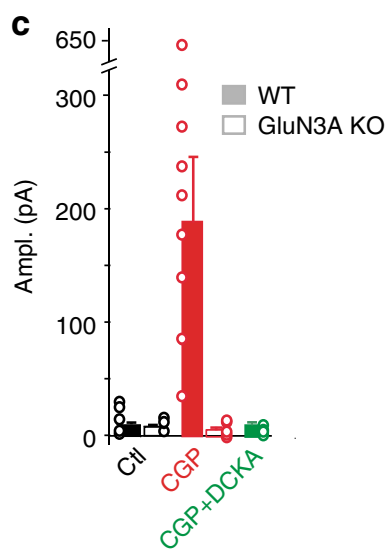

Fig. 5 GluN1/GluN3A receptors are expressed and functional in juvenile hippocampal slices. a Schematic representation of the experimental protocol. Glycine $(10 \mathrm{mM})$ is puffed onto voltage-clamped CA1 cells in acute hippocampal slices from young (P8-12) mice. b In control conditions, glycine puffs trigger very small inward currents in both wild-type (WT) and GluN3A-KO mice (upper black traces on both left and right). A typical response obtained in WT mice is shown at larger magnification and time scale in the top left inset. Bath application of CGP-78608 (CGP) leads to massive potentiation of glycine-elicited currents in WT mice, but has no effect in GluN3A-KO animals (bottom red traces). In WT mice, addition of DCKA (500 $\mu$ M), a GluN1 and GluN3A glycine-binding site antagonist, eliminates currents obtained in the presence of CGP-78608 (bottom left green trace), thus further confirming that GluN1/GluN3A receptors mediate the responses to glycine. c Quantification of the experimental results obtained in panel b. WT mice, full bars; GluN3A$\mathrm{KO}$ mice, empty bars. Data are illustrated as mean \pm SEM

application of DCKA $(500 \mu \mathrm{M})$, a dual GluN1 and GluN3 glycine-binding site antagonist ${ }^{10,24}$, almost fully abolished the currents obtained in the presence of CGP-78608 (10.2 $\pm 2.7 \mathrm{pA}$ $[n=9] ; P=0.001$; Mann-Whitney test). Altogether, these results provide the first demonstration that glycine excitatory GluN1/ GluN3A receptors are expressed and functional in juvenile neurons. Moreover, they highlight the power of CGP-78608 as a new tool compound for detecting GluN1/GluN3A receptor conductances in native systems.

\section{Discussion}

In many aspects, the functional properties and physiological relevance of excitatory glycine GluN1/GluN3 NMDARs remain a conundrum. Here, we provide novel information on the activation, modulation, and pharmacology of GluN1/GluN3A receptors, as well as on their expression in native neurons. We identify a small molecule compound that massively potentiates and extensively transforms GluN1/GluN3A receptor responses. Moreover, we show that GluN1/GluN3A receptors can switch between two distinct modes of activation with very different agonist responsiveness and kinetics, in a redox-dependent manner. We identify an endogenous GluN3A disulfide bridge, as the main molecular actor responsible for this functional plasticity. Finally, we demonstrate that glycine excitatory GluN1/GluN3A receptors can indeed be expressed and be functional in native systems. Hence, these receptors are not just artefacts of heterologous expression systems. Our work thus transforms our current understanding of these underappreciated receptors, and clarifies the long-standing doubts concerning their presence in brain neurons. By providing new ways to manipulate and interrogate GluN1/GluN3A receptors, our work should also facilitate the search for their physiological function.

Building on the differential contribution of the GluN1 and GluN3A subunits to GluN1/GluN3A receptor activation, we discovered that the GluN1 antagonist CGP-78608 acts as a highly potent and powerful potentiator of GluN1/GluN3A receptors. The extent of current potentiation produced by this compound several orders of magnitude - greatly exceeds effects previously reported by other GluN1 glycine-binding site antagonists. Moreover, CGP-78608 profoundly transformed the time course of GluN1/GluN3A responses, rendering them much less transient. The enhanced peak amplitude together with the enhanced response stability results in a striking awakening phenotype consisting in a massive overall increase in charge transfer, uncommon in receptor pharmacology. Indeed, many positive allosteric modulators enhance current amplitude without major impact on current time course ${ }^{47}$. Alternatively, drugs can drastically change current shape while having virtually no effect on peak current amplitude, as observed with cyclothiazide on AMPA receptors ${ }^{48}$. The uniqueness of CGP-78608 likely stems from the atypical mechanism of GluN1/GluN3A receptor activation where the same molecule, glycine, serves both as an agonist and a functional antagonist ${ }^{23,24}$. With its high selectivity for GluN1 over GluN3A ABD ${ }^{11}$, we suggest that CGP-78608 prevents glycine antagonist effects at GluN1 ABD sites while interfering minimally with the glycine agonist effects at GluN3 ABD sites. In an attempt to formalize this, and other modulatory and gating reactions observed at GluN1/GluN3A receptors, a simple schematic model is proposed (Fig. 6). In this scheme, GluN1/GluN3A receptors can adopt four discrete states along the activation pathway: one resting and one active state, and two desensitized states (Fig. 6a). Upon glycine application, two events resulting in two separate effects occur: receptor activation (i.e. pore opening) by glycine binding to GluN3 sites; receptor inhibition (i.e. entry into desensitized states) following glycine binding to GluN1 sites. These effects can occur either concurrently or sequentially, because GluN3A sites have higher glycine affinity than GluN1 sites ${ }^{11}$. Therefore, exposure to high glycine concentrations leads to small, transient, and rapidly desensitizing responses (Resting- > Active- > Des2; Fig. 6a). Pre-incubation of CGP-78608 prior to glycine application (Pre; Fig. 6b) locks the GluN1 ABD in the open clamshell conformation and prevents glycine binding to GluN1 (Fig. 6b). Little or no CGP-78608 binds to GluN3 given its strong preference for GluN1 ( 1000-fold selectivity factor $\left.{ }^{11}\right)$. Following application of saturating glycine, all GluN3 sites are occupied and the receptors fully activate. Meanwhile, little displacement of CGP-78608 from GluN1 sites by glycine occurs, CGP-78608 having much higher affinity as manifested by its long residency time ( $\tau_{\text {off }}$ in the second timescale, see Fig. 2 ). Hence, the receptors are stabilized in the active state and avoid desensitization, explaining the massive potentiation produced by CGP- 

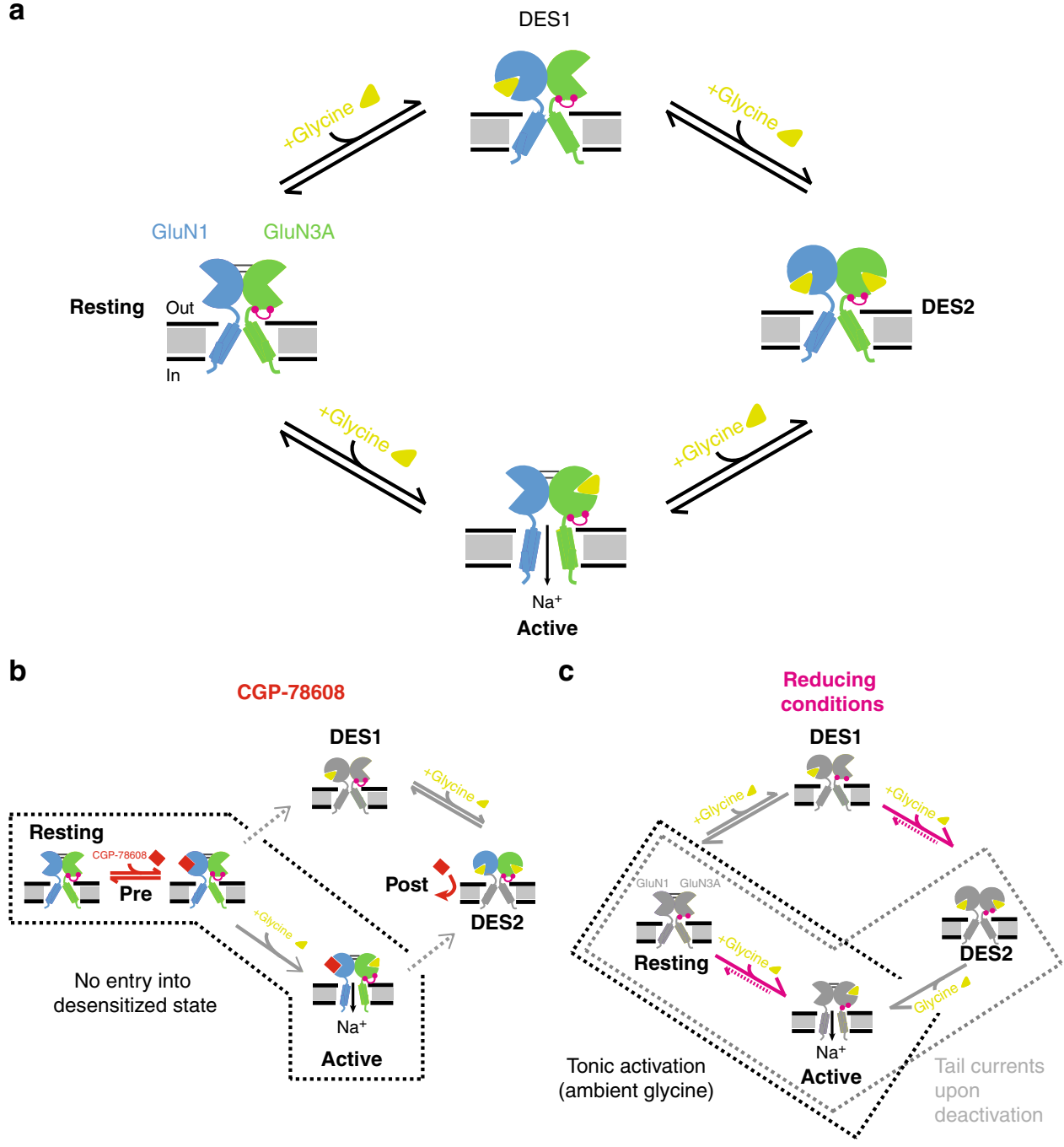

Fig. 6 Schematic model of GluN1/GluN3A activation and modulation. For clarity, a single GluN1/GluN3A dimer is shown and the NTDs omitted. The upper scheme (a) shows receptor activation in control conditions. The GluN3A disulfide bridge conferring high redox sensitivity is highlighted in pink. The lower left scheme (b) illustrates activation sequence in presence of CGP-78608. Pre indicates application of CGP-78608 before glycine application while Post indicates the opposite. Pre-incubation with CGP-78608 prior to glycine application enhances receptor activity by preventing glycine binding to GluN1 and subsequent entry into desensitized states. The lower right scheme (c) illustrates activation sequence of reduced receptors (GluN3A ABD lower lobe disulfide bridge broken). The main modification is a large increase in the affinity of the GluN3A ABD for glycine resulting in tonic receptor activation by ambient glycine

78608. A different scenario occurs when CGP-78608 is applied after glycine (Post; Fig. 6b). Glycine application shifts most of the receptors into a long-lived glycine-bound desensitized state that would adopt a conformation strongly diminishing CGP-78608 binding. Accordingly, little CGP-78608 potentiation is observed. Increased glycine affinity of GluN1 sites of desensitized receptors likely contributes to this strong state-dependence. Several GluN1/ GluN2 modulators also show strong state-dependence (e.g. refs. ${ }^{49,50}$ ), highlighting the importance of receptor conformational landscape in NMDAR pharmacology. The much greater effects of CGP-78608 compared to other GluN1 antagonists (Fig. 1c, d) likely finds its origin from a unique combination of high potency/high selectivity of CGP-78608 for GluN1 ABD sites. The molecular basis of this unique pharmacological profile still remains to be understood. Binding studies on isolated domains indicate that L689650 discriminates between GluN1 and GluN3 ABDs even better than CGP-78608 ${ }^{11}$, yet functional effects of L689650 on full-length receptors are much smaller than those produced by CGP-78608 (Fig. 1c, d). The phosphonate group of
CGP-78608, absent in other tested compounds, could make the difference with its specific chemistry (by stabilizing specific $\mathrm{ABD} /$ receptor conformations). Ultimately, structures of GluN3Aantagonist complexes should allow determining how CGP78608 singles out from other GluN1 antagonists.

The robustness of GluN1/GluN3A receptor expression in heterologous systems has been questioned ever since the cloning of GluN3A. Several attempts failed to detect noticeable current responses following co-expression of GluN1 and GluN3A subunits, be it in Xenopus oocytes ${ }^{7}$ or HEK cells ${ }^{29,51}$. In studies examining functional GluN1/GluN3 receptors ${ }^{23,24,31,52}$, current responses in control conditions are most often small and transient, complicating their analysis. Our results show that glycinetriggered currents barely detectable in control conditions turn into large and sustained responses in the presence of CGP-78608. This demonstrates that excitatory glycine GluN1/GluN3A receptors express very robustly in heterologous systems, at levels comparable to those of GluN1/GluN2 NMDARs. Our redox experiments further establish that GluN1/GluN3A receptor 
activability strongly depends on the receptor's microenvironment. We show that depending on the redox state, the receptor can adopt two radically different gating modes, resulting in different current size and shape. The variability in redox state between experimental settings could thus explain, at least in part, the inconsistency and heterogeneity of GluN1/GluN3A receptor responses previously reported in the literature.

Our redox and mutagenesis experiments reveal that a single endogenous disulfide bridge on the GluN3A subunit - GluN3AC859-C913 - has major influence on the activation properties of GluN1/GluN3A receptors. This bridge acts as a redox-sensitive gating switch that controls the receptor's glycine affinity and gating kinetics. Under oxidizing conditions, when the two cysteines are cross-linked, the receptor displays a glycine sensitivity in the micromolar range, and a typical activationdesensitization-deactivation pattern upon application of high glycine concentrations. Under reducing conditions, when the disulfide bridge is broken, the gating pattern changes completely. The main modification is a large increase in the GluN3A ABD glycine affinity, estimated between one and two orders of magnitude, and manifested by extremely slow glycine dissociation kinetics from activating GluN3A sites. The enhancement in glycine affinity is such that low ambient glycine concentrations (in the nanomolar range) known to contaminate recording solutions ${ }^{4-46}$ are sufficient to occupy high-affinity GluN3A sites (but not low-affinity GluN1 sites) and constitutively activate (a fraction of) GluN1/GluN3A receptors. When high glycine concentrations are applied, all receptors activate and then rapidly desensitize, accumulating in the Des2 state (Fig. 6c). This also concerns receptors activated prior to glycine application, which desensitize following glycine binding to unoccupied GluN1 sites, thus explaining the outward current shift observed in the steadystate. Upon its removal, glycine unbinds rapidly from (low-affinity) GluN1 sites but not from (high-affinity) GluN3A sites. Therefore, as they return to the resting state, receptors transit through the GluN3A-only bound state, the sole active state, accounting for the large tail currents. In such a scenario, tail current deactivation kinetics should closely match glycine dissociation kinetics. This is what is observed (Supplementary Figure 3). Unusual current phenotypes strikingly similar to those described here with constitutive activation, outward shifted steady-state currents and large tail currents have been recently described for kainate receptors harboring clinically-relevant mutations in their transmembrane region ${ }^{53}$. These effects are best explained by profoundly altered gating properties - exquisite sensitivity to ambient agonist (i.e. glutamate) and reopening of receptors as they recover from desensitization ${ }^{53,54}$-as we propose here for glycine excitatory GluN1/GluN3A receptors under reducing conditions. The GluN3A-C859-C913 disulfide bridge occupies a strategic location in GluN3 $\mathrm{A}^{12,55}$, connecting the $\mathrm{ABD}$ lower lobe to the TMD ion channel ${ }^{56,57}$. We speculate that its removal releases constraints on the GluN3A ABD clamshell, favoring domain closure, agonist (glycine) binding, and opening of the channel gate. A similar mechanism may also be at play at GluN1 subunits ${ }^{58}$, although effects on receptor gating appear much more limited.

By disclosing novel gating and modulation properties of GluN1/GluN3A receptors, our work brings out several important points. First, these receptors are highly plastic in their functionality, capable of operating under various regimes (low/high agonist affinity; transient/persistent activity) according to their environment (redox state). Second, from a molecular and cellular perspective, GluN1/GluN3A receptors are not weakly expressing receptors; on the contrary, they express at high levels, although they appear to be strongly inhibited (or apt to be inhibited) in control conditions. This latter finding is particularly important on a physiological point of view. The function and identification of native excitatory glycine GluN1/GluN3A receptors have been pending for years. We now reveal that this is not due to a lack of expression but to problems in their detection. Using the GluN1antagonist CGP-78608 as a novel tool compound to prevent receptor auto-inhibition by glycine, we now show that GluN1/ GluN3A receptors are robustly expressed, and electrically functional, in neurons of the juvenile brain. Without the pharmacological assistance of CGP-78608, the GluN1/GluN3A current responses remain virtually undetectable, thus explaining the lack of information on their functional expression until now. Under normal conditions, the activity of excitatory glycine GluN1/ GluN3A receptors may be particularly prone to desensitization, or operate under a low tonic regime, as described for persistent inhibitory GABA-A conductances ${ }^{59}$. Our discovery of the powerful awakening effect of CGP-78608 and of the redox switch of GluN1/GluN3A receptors opens new perspectives on the exploration of excitatory glycine receptors and their role in brain development and function.

\section{Methods}

Ethical statement. All procedures involving experimental animals were performed in accordance with the European directive 2010/63/EU on the Protection of Animals used for Scientific Purposes, the guidelines of the French Agriculture and Forestry Ministry for handling animals, and local ethics committee guidelines.

Molecular biology. The pcDNA3-based plasmid encoding the rat GluN1-4a subunit that was used throughout this work was a kind gift from John Woodward (Medical University of South Carolina, USA). The variant GluN1-4a (named GluN1 herein) was preferred to other GluN1 splice variants because of better assembly into functional diheteromeric GluN1/GluN3 receptors ${ }^{30}$. The pcI_NEO plasmid encoding the rat GluN3A subunit was a kind gift from Isabel Perez-Otaño (Universidad de Navarra, Spain). Site-directed mutagenesis and sequencing procedures were performed as previously described ${ }^{60}$.

Two-electrode voltage-clamp recordings. Oocytes from Xenopus loevis (Xenopus Express, Rennes, France) were used for heterologous expression of recombinant GluN1/GluN3A receptors studied using two-electrode voltage-clamp (TEVC). TEVC recordings were performed 3-4 days following injection. Harvesting and preparation of oocytes was performed as previously described ${ }^{60}$ and in the framework of project authorization \#05137.02 as delivered by the French Ministry of Education and Research. Each oocyte was co-injected with a mixture of GluN1 and GluN3A cDNA at a concentration of $50 \mathrm{ng} / \mu \mathrm{l}$ and at a $1: 1$ ratio. The standard external solution contained (in $\mathrm{mM}$ ): $100 \mathrm{NaCl}, 2.5 \mathrm{KCl}, 0.3 \mathrm{BaCl}_{2}, 5 \mathrm{HEPES}, 0.01$ DTPA (diethylenetriamine-pentaacetic acid), $\mathrm{pH}$ 7.3. Treatments with the reducing agent DTE (dithioerythritol, $5 \mathrm{mM}$ ) were performed at room temperature during 15-20 min in a Barth solution. Recordings were performed at $-60 \mathrm{mV}$ and at room temperature. Currents were sampled at $100 \mathrm{~Hz}$ and low-pass filtered at $20 \mathrm{~Hz}$ using an Oocyte Clamp OC-725 amplifier and pClamp 10.5 (Molecular devices). Data analysis was performed using Clampfit 10.5 and Kaleidagraph4 (Synergy Software).

Whole-cell patch-clamp recordings in HEK cells. HEK293 cells were used for heterologous expression of recombinant GluN1/GluN3 receptors studied using whole-cell patch-clamp. Cells were obtained from ECACC (European Collection of Authenticated Cell Culture, catalog number: 96121229) and cultured under standard cell culture conditions $\left(95 / 5 \% \mathrm{O}_{2} / \mathrm{CO}_{2}\right.$ mixture, $\left.37^{\circ} \mathrm{C}\right)$. Cells were transfected using polyethylenimine with GluN1, GluN3A and GFP plasmids at a 1:3:1 ratio $(0.3,0.9$ and $0.3 \mathrm{ng} / \mu \mathrm{l}$ respectively). Recordings were performed $24-48 \mathrm{~h}$ following cell transfection. The extracellular solution contained (in $\mathrm{mM}$ ): $140 \mathrm{NaCl}, 2.8 \mathrm{KCl}$, $1 \mathrm{CaCl}_{2}, 10 \mathrm{HEPES}$ and 20 Sucrose (290-300 mOsm), $\mathrm{pH}$ adjusted to 7.3 using $\mathrm{NaOH}$. The pipette solution contained (in mM): $115 \mathrm{CsF}, 10 \mathrm{CsCl}, 10 \mathrm{HEPES}$ and 10 BAPTA (280-290 mOsm), pH adjusted to 7.2 using $\mathrm{CsOH}$. Currents were sampled at $10 \mathrm{kHz}$ and low-pass filtered at $2 \mathrm{kHz}$ using an Axopatch $200 \mathrm{~B}$ amplifier and Clampex 10.6. Drugs and agonists were applied using a multi-barrel solution exchanger (RSC 200; Bio-logic). Recordings were performed at $-60 \mathrm{mV}$ and at room temperature. In experiments with reducing agents, cells were pre-incubated in external solution with Tris(2-carboxyethyl)phosphine (TCEP, $5 \mathrm{mM}$ ) or reduced glutathione (GSH, $50 \mathrm{mM}$ ) during $20 \mathrm{~min}$.

Whole-cell patch-clamp recordings in CA1 pyramidal cells. Ex-vivo electrophysiological experiments were performed on coronal slices from the brains of juvenile wild-type (WT) and GluN3A-KO mice originating from the same litters (8-12 days old). Slices were prepared as described previously ${ }^{61}$. Briefly, mice were anesthetized with isofluorane before decapitation. After isolation, the portion of the 
brain containing the hippocampus was placed in bicarbonate-buffered saline (BBS) at $2-5^{\circ} \mathrm{C}$ for a few minutes. Slices $(300 \mu \mathrm{m})$ were then cut using a $7000 \mathrm{smz}-2$ vibratome (Campden). The slicing procedure was performed in an ice-cold solution containing (in $\mathrm{mM}$ ): $130 \mathrm{~K}^{+}$- gluconate, $15 \mathrm{KCl}, 0.05 \mathrm{EGTA}, 20$ Hepes, 25 glucose, $1 \mathrm{CaCl}_{2}$, and $6 \mathrm{MgCl}_{2}$ supplemented with DL-APV $(50 \mu \mathrm{M})$. Slices were then transferred for a few minutes to a solution containing (in $\mathrm{mM}$ ): $225 \mathrm{D}$ mannitol, $2.5 \mathrm{KCl}, 1.25 \mathrm{NaH}_{2} \mathrm{PO}_{4}, 25 \mathrm{NaHCO}_{3}$, 25 glucose, $1 \mathrm{CaCl}_{2}$, and $6 \mathrm{MgCl}_{2}$, and finally stored for the rest of the experimental day at $32-34{ }^{\circ} \mathrm{C}$ in oxygenated BBS, containing (in mM): $115 \mathrm{NaCl}, 2.5 \mathrm{KCl}, 1.6 \mathrm{CaCl}_{2}, 1.5 \mathrm{MgCl}_{2}, 1.25 \mathrm{NaH}_{2} \mathrm{PO}_{4}$, $26 \mathrm{NaHCO}_{3}$, and 30 glucose (pH 7.4 after equilibration with $95 \% \mathrm{O}_{2}$ and $5 \% \mathrm{CO}_{2}$ ). For all recordings, slices were continuously superfused at $32-34^{\circ} \mathrm{C}$ with oxygenated BBS supplemented with NBQX (10 $\mu \mathrm{M}$; Tocris), SR95-531 (5 $\mu \mathrm{M}$; Tocris), strychnine $(50 \mu \mathrm{M}$; Sigma), and TTX (500 nM; Latoxan).

CA1 neurons were recorded from both the ventral and the dorsal hippocampus. Cells were visualized with a combination of Dodt contrast, and an on-line video contrast enhancement. CA1 cells could be easily identified in the red light with which slices were visualized using a CoolSnap HQ2 CCD camera (Photometrics) run by MetaMorph (Universal Imaging). Whole-cell recordings were performed with an EPC-10 double amplifier (Heka Elektronik) run by PatchMaster (Heka). Patch pipettes (resistance 2-3 M $\Omega$ ) were filled with an intracellular solution containing (in mM): $120 \mathrm{CsMeSO}_{3}, 4.6 \mathrm{MgCl}_{2}, 10 \mathrm{HEPES}, 10 \mathrm{~K}_{2}$-creatine phosphate, 15 BAPTA, $4 \mathrm{Na}_{2}$-ATP, $0.4 \mathrm{Na}_{2}$-GTP, 1 QX-314, pH 7.35 with $\mathrm{CsOH}$ $(\sim 300 \mathrm{mOsm})$. Series resistance was partially compensated ( $\max 65 \%)$, whereas liquid junction potentials were not corrected. Recordings were performed at a holding potential of $-60 \mathrm{mV}$. Puffing pipettes filled with BBS supplemented with glycine $(10 \mathrm{mM})$, NBQX $(2 \mu \mathrm{M})$, SR95-531 $(2 \mu \mathrm{M})$, strychnine $(50 \mu \mathrm{M})$, and DAPV $(100 \mu \mathrm{M})$, were placed above the slice surface, close to the recording pipettes. Brief $(0.5-1$ s) puffs were then delivered every $60-120 \mathrm{~s}$ via a Picospritzer II (General Valve Corporation).

Pharmacology and data analysis. CGP-78608 dose-response curve (DRC) experiments were performed using $100 \mu \mathrm{M}$ glycine. In these, and most other, experiments, CGP-78608 was systematically applied before agonist perfusion. CGP-78608 DRC was fitted using the following equation: $I_{\mathrm{rel}}=1+((a-1) /(1+$ $\left([C] / \mathrm{EC}_{50}\right)^{n \mathrm{H}}$ ) were $[C]$ is the compound concentration, $a$ is the maximal poten tiation and $n_{\mathrm{H}}$ the Hill coefficient. $\mathrm{EC}_{50}, a$ and $n_{\mathrm{H}}$ were set as free parameters. Agonist DRCs were fitted with the following Hill equation: $I_{\mathrm{rel}}=1 /\left(1+\left(\mathrm{EC}_{50} /[A]\right)\right.$ $n \mathrm{H})$, were $[A]$ is the agonist concentration, and $\mathrm{EC}_{50}$ and $n_{\mathrm{H}}$ set as free parameters. Desensitization and glycine or CGP-78608 washout kinetics were fitted using single exponentials with Clampfit 10.5 analysis software. When comparing the effects of various GluN1 competitive antagonists on GluN1/GluN3A current responses, glycine was used at $1 \mathrm{mM}$. To insure sufficient GluN1 binding site occupancy, the concentrations of CGP-78608 (500 nM), MDL-29951 (200 nM), 7-CKA (10 $\mu \mathrm{M})$, and $\mathrm{L} 689560(1 \mu \mathrm{M})$ were set above their Ki values for GluN1 ABD (6.4 nM, 140 $\mathrm{nM}, 2.6 \mu \mathrm{M}, 29.3 \mathrm{nM}$; radiolabeled glycine displacement assays on isolated domains $^{11}$ or native receptors for MDL-29951 ${ }^{62}$ ). For MDL-29951, in order to insure that larger effects may have not been missed, a higher concentration was also tested $(2 \mu \mathrm{M})$, yet potentiating factors were found to be smaller than those observed at $200 \mathrm{nM}$. This is likely due to MDL-29951 binding at GluN3A ABD and inhibiting GluN1/GluN3A receptors.

The compound [(1 S)-1-[[(7-Bromo-1,2,3,4-tetrahydro-2,3-dioxo-5quinoxalinyl)methyl]amino] ethyl]phosphonic acid hydrochloride (CGP-78608, Tocris) was prepared as a stock solution of $25 \mathrm{mM}$ in $2.2 \mathrm{eq} \mathrm{NaOH}$ solution. 2carboxy-4,6-dichloro-1H-indole-3-propanoic acid (MDL-29951, Cayman Chemical), 7-Chlorokynureic acid (7-CKA, Tocris), trans-2-Carboxy-5, 7-dichloro-4-phenylaminocarbonylamino-1,2,3,4-tetrahydroquinoline (L689560, Tocris) and 6-Cyano-7-nitroquinoxaline-2,3-dione (CNQX, Alomone) were prepared in DMSO at stock concentrations of $2 \mathrm{mM}, 10 \mathrm{mM}, 2 \mathrm{mM}$, and $50 \mathrm{mM}$, respectively. 5-7-Dichlorokynurenic acid (DCKA, Tocris) stocks (50 $\mathrm{mM})$ were prepared in a 1 eq $\mathrm{NaOH}$ solution. Glycine $(1 \mathrm{mM}$; Sigma), strychnine $(10 \mathrm{mM}$; Sigma), 6-Imino-3-(4-methoxyphenyl)-1 $(6 \mathrm{H})$-pyridazinebutanoic acid hydrobromide (SR95-531; 10 mM; Tocris), 2,3-Dioxo-6-nitro-1,2,3,4 tetrahydrobenzo[f] quinoxaline-7-sulfonamide disodium salt (NBQX;10 mM; Tocris), D-(-)-2-Amino-5-phosphonopentanoic acid (D-APV; $50 \mathrm{mM}$; Tocris) stocks were all prepared in water. Finally, Tetrodotoxin (TTX; $500 \mu \mathrm{M}$; Latoxan) was aliquoted in an acetic acid (2\%) water solution.

Statistical analysis. Data are presented as mean \pm standard error of the mean (SEM). Sample number $(n)$ refers either to the number of recorded oocytes or HEK293 cells (Figs. 1-4), or to the number of recorded CA1 cells (Fig. 5). Unless otherwise stated, two-sided statistical analysis of the data shown in Figs. 1-4 was conducted using either two sample Student's $t$-test or the Mann-Whitney test when Equal Variance test failed. Data obtained from different conditions in Fig. 5 were compared statistically either with Mann-Whitney or Wilcoxon signed-rank test, as indicated in the text. Tests were performed using either SigmaPlot (Systat Software) or house-built routines in Igor (Wavemetrics). Statistical significance is reported in the figures according to the following symbols ${ }^{*},{ }^{*}$ and ${ }^{* * *}$, which indicate $P$ values below $0.05,0.01$, and 0.001 , respectively. n.s. $=$ not significant

\section{Data availability}

The datasets generated and analysed during the current study are available from the corresponding authors on reasonable request.

Received: 15 May 2018 Accepted: 12 October 2018

Published online: 13 November 2018

\section{References}

1. Traynelis, S. F. et al. Glutamate receptor ion channels: structure, regulation, and function. Pharmacol. Rev. 62, 405-496 (2010).

2. Paoletti, P., Bellone, C. \& Zhou, Q. NMDA receptor subunit diversity: impact on receptor properties, synaptic plasticity and disease. Nat. Rev. Neurosci. 14 383-400 (2013).

3. Sanz-Clemente, A., Nicoll, R. A. \& Roche, K. W. Diversity in NMDA receptor composition: many regulators, many consequences. Neuroscientist 19, 62-75 (2013).

4. Paoletti, P. Molecular basis of NMDA receptor functional diversity. Eur. J. Neurosci. 33, 1351-1365 (2011).

5. Bliss, T. V. \& Collingridge, G. L. A synaptic model of memory: long-term potentiation in the hippocampus. Nature 361, 31-39 (1993).

6. Ciabarra, A. M. et al. Cloning and characterization of chi-1: a developmentally regulated member of a novel class of the ionotropic glutamate receptor family. J. Neurosci. 15, 6498-6508 (1995).

7. Sucher, N. J. et al. Developmental and regional expression pattern of a novel NMDA receptor-like subunit (NMDAR-L) in the rodent brain. J. Neurosci. 15, 6509-6520 (1995).

8. Andersson, O., Stenqvist, A., Attersand, A. \& von Euler, G. Nucleotide sequence, genomic organization, and chromosomal localization of genes encoding the human NMDA receptor subunits NR3A and NR3B. Genomics 78, 178-184 (2001)

9. Nishi, M., Hinds, H., Lu, H. P., Kawata, M. \& Hayashi, Y. Motoneuronspecific expression of NR3B, a novel NMDA-type glutamate receptor subunit that works in a dominant-negative manner. J. Neurosci. 21, RC185 (2001).

10. Chatterton, J. E. et al. Excitatory glycine receptors containing the NR3 family of NMDA receptor subunits. Nature 415, 793-798 (2002).

11. Yao, Y. \& Mayer, M. L. Characterization of a soluble ligand binding domain of the NMDA receptor regulatory subunit NR3A. J. Neurosci. 26, 4559-4566 (2006).

12. Yao, Y., Harrison, C. B., Freddolino, P. L., Schulten, K. \& Mayer, M. L. Molecular mechanism of ligand recognition by NR3 subtype glutamate receptors. EMBO J. 27, 2158-2170 (2008).

13. Das, S. et al. Increased NMDA current and spine density in mice lacking the NMDA receptor subunit NR3A. Nature 393, 377-381 (1998).

14. Roberts, A. C. et al. Downregulation of NR3A-containing NMDARs is required for synapse maturation and memory consolidation. Neuron 63, 342-356 (2009).

15. Larsen, R. S. et al. NR3A-containing NMDARs promote neurotransmitter release and spike timing-dependent plasticity. Nat. Neurosci. 14, 338-344 (2011).

16. Wong, H. K. et al. Temporal and regional expression of NMDA receptor subunit NR3A in the mammalian brain. J. Comp. Neurol. 450, 303-317 (2002).

17. Wee, K. S., Zhang, Y., Khanna, S. \& Low, C. M. Immunolocalization of NMDA receptor subuhnit NR3B in selected structures in the rat forebrain, cerebellum, and lumbar spinal cord. J. Comp. Neurol. 509, 118-135 (2008).

18. Henson, M. A., Roberts, A. C., Perez-Otano, I. \& Philpot, B. D. Influence of the NR3A subunit on NMDA receptor functions. Prog. Neurobiol. 91, 23-37 (2010).

19. Pachernegg, S., Strutz-Seebohm, N. \& Hollmann, M. GluN3 subunitcontaining NMDA receptors: not just one-trick ponies. Trends Neurosci. 35, 240-249 (2012).

20. Perez-Otano, I., Larsen, R. S. \& Wesseling, J. F. Emerging roles of GluN3containing NMDA receptors in the CNS. Nat. Rev. Neurosci. 17, 623-635 (2016).

21. Perez-Otano, I. et al. Assembly with the NR1 subunit is required for surface expression of NR3A-containing NMDA receptors. J. Neurosci. 21, 1228-1237 (2001).

22. Sasaki, Y. F. et al. Characterization and comparison of the NR3A subunit of the NMDA receptor in recombinant systems and primary cortical neurons. J. Neurophysiol. 87, 2052-2063 (2002).

23. Madry, C. et al. Principal role of NR3 subunits in NR1/NR3 excitatory glycine receptor function. Biochem. Biophys. Res. Commun. 354, 102-108 (2007).

24. Awobuluyi, M. et al. Subunit-specific roles of glycine-binding domains in activation of NR1/NR3 N-methyl-D-aspartate receptors. Mol. Pharmacol. 71, 112-122 (2007). 
25. Curtis, D. R. et al. Inhibition of spinal neurons by glycine. Nature 215, 1502-1503 (1967).

26. Legendre, P. The glycinergic inhibitory synapse. Cell. Mol. Life Sci. 58, 760-793 (2001).

27. Bowery, N. G. \& Smart, T. G. GABA and glycine as neurotransmitters: a brief history. Br. J. Pharmacol. 147, S109-S119 (2006).

28. Pina-Crespo, J. C. et al. Excitatory glycine responses of CNS myelin mediated by NR1/NR3 "NMDA" receptor subunits. J. Neurosci. 30, 11501-11505 (2010).

29. Smothers, C. T. \& Woodward, J. J. Pharmacological characterization of glycine-activated currents in HEK 293 cells expressing N-methylD-aspartate NR1 and NR3 subunits. J. Pharmacol. Exp. Ther. 322, 739-748 (2007).

30. Smothers, C. T. \& Woodward, J. J. Expression of glycine-activated diheteromeric NR1/NR3 receptors in human embryonic kidney 293 cells Is NR1 splice variant-dependent. J. Pharmacol. Exp. Ther. 331, 975-984 (2009).

31. Cummings, K. A., Belin, S. \& Popescu, G. K. Residues in the GluN1 Cterminal domain control kinetics and pharmacology of GluN1/GluN3A Nmethyl-d-aspartate receptors. Neuropharmacology 119, 40-47 (2017).

32. Madry, C., Betz, H., Geiger, J. R. \& Laube, B. Supralinear potentiation of NR1/NR3A excitatory glycine receptors by $\mathrm{Zn}^{2+}$ and NR1 antagonist. Proc. Natl Acad. Sci. USA 105, 12563-12568 (2008).

33. Kvist, T., Greenwood, J. R., Hansen, K. B., Traynelis, S. F. \& Brauner-Osborne, H. Structure-based discovery of antagonists for GluN3-containing N-methylD-aspartate receptors. Neuropharmacology 75, 324-336 (2013).

34. Cummings, K. A. \& Popescu, G. K. Protons potentiate GluN1/GluN3A currents by attenuating their desensitisation. Sci. Rep. 6, 23344 (2016).

35. Auberson, Y. P. et al. N-phosphonoalkyl-5-aminomethylquinoxaline-2,3diones: in vivo active AMPA and NMDA(glycine) antagonists. Bioorg. Med. Chem. Lett. 9, 249-254 (1999).

36. Aizenman, E., Lipton, S. A. \& Loring, R. H. Selective modulation of NMDA responses by reduction and oxidation. Neuron 2, 1257-1263 (1989).

37. Kohr, G., Eckardt, S., Luddens, H., Monyer, H. \& Seeburg, P. H. NMDA receptor channels: subunit-specific potentiation by reducing agents. Neuron 12, 1031-1040 (1994).

38. Sullivan, J. M. et al. Identification of two cysteine residues that are required for redox modulation of the NMDA subtype of glutamate receptor. Neuron 13, 929-936 (1994).

39. Choi, Y. B. \& Lipton, S. A. Redox modulation of the NMDA receptor. Cell. Mol. Life Sci. 57, 1535-1541 (2000).

40. Sanchez, R. M. et al. Novel role for the NMDA receptor redox modulatory site in the pathophysiology of seizures. J. Neurosci. 20, 2409-2417 (2000).

41. Yang, Y. J. et al. Reversal of aging-associated hippocampal synaptic plasticity deficits by reductants via regulation of thiol redox and NMDA receptor function. Aging Cell. 9, 709-721 (2010).

42. Kumar, A. \& Foster, T. C. Linking redox regulation of NMDAR synaptic function to cognitive decline during aging. J. Neurosci. 33, 15710-15715 (2013).

43. Kim, J. Y., Ko, A. R., Hyun, H. W., Min, S. J. \& Kim, J. E. PDI regulates seizure activity via NMDA receptor redox in rats. Sci. Rep. 7, 42491 (2017).

44. Kleckner, N. W. \& Dingledine, R. Requirement for glycine in activation of NMDA-receptors expressed in Xenopusoocytes. Science 241, 835-837 (1988).

45. Lerma, J., Zukin, R. S. \& Bennett, M. V. Glycine decreases desensitization of $\mathrm{N}$-methyl-D-aspartate (NMDA) receptors expressed in Xenopusoocytes and is required for NMDA responses. Proc. Natl Acad. Sci. USA 87, 2354-2358 (1990).

46. Johnson, J. W. \& Ascher, P. Equilibrium and kinetic study of glycine action on the N-methyl-D-aspartate receptor in cultured mouse brain neurons. J. Physiol. 455, 339-365 (1992).

47. Hackos, D. H. \& Hanson, J. E. Diverse modes of NMDA receptor positive allosteric modulation: mechanisms and consequences. Neuropharmacology 112, 34-45 (2017).

48. Sun, Y. et al. Mechanism of glutamate receptor desensitization. Nature 417, 245-253 (2002).

49. Horak, M., Vlcek, K., Petrovic, M., Chodounska, H. \& Vyklicky, L. Jr. Molecular mechanism of pregnenolone sulfate action at NR1/NR2B receptors. J. Neurosci. 24, 10318-10325 (2004).

50. Yi, F. et al. Structural basis for negative allosteric modulation of GluN2Acontaining NMDA receptors. Neuron 91, 1316-1329 (2016).

51. Matsuda, K., Fletcher, M., Kamiya, Y. \& Yuzaki, M. Specific assembly with the NMDA receptor $3 \mathrm{~B}$ subunit controls surface expression and calcium permeability of NMDA receptors. J. Neurosci. 23, 10064-10073 (2003).

52. Mesic, I. et al. The N-terminal domain of the GluN3A subunit determines the efficacy of glycine-activated NMDA receptors. Neuropharmacology 105 , 133-141 (2016).
53. Guzman, Y. F. et al. A gain-of-function mutation in the GRIK2 gene causes neurodevelopmental deficits. Neurology 3, 129 (2017)

54. Lu, H. W., Balmer, T. S., Romero, G. E. \& Trussell, L. O. Slow AMPAR synaptic transmission is determined by stargazin and glutamate transporters. Neuron 96, 73-80 (2017)

55. Yao, Y., Belcher, J., Berger, A. J., Mayer, M. L. \& Lau, A. Y. Conformational analysis of NMDA receptor GluN1, GluN2, and GluN3 ligand-binding domains reveals subtype-specific characteristics. Structure 21, 1788-1799 (2013).

56. Karakas, E. \& Furukawa, H. Crystal structure of a heterotetrameric NMDA receptor ion channel. Science 344, 992-997 (2014).

57. Lee, C. H. et al. NMDA receptor structures reveal subunit arrangement and pore architecture. Nature 511, 191-197 (2014).

58. Furukawa, H. \& Gouaux, E. Mechanisms of activation, inhibition and specificity: crystal structures of the NMDA receptor NR1 ligand-binding core. EMBO J. 22, 2873-2885 (2003).

59. Semyanov, A., Walker, M. C., Kullmann, D. M. \& Silver, R. A. Tonically active GABA A receptors: modulating gain and maintaining the tone. Trends Neurosci. 27, 262-269 (2004)

60. Mony, L., Zhu, S., Carvalho, S. \& Paoletti, P. Molecular basis of positive allosteric modulation of GluN2B NMDA receptors by polyamines. EMBO J. 30, 3134-3146 (2011).

61. Otsu, Y. et al. Functional principles of posterior septal inputs to the medial habenula. Cell Rep. 22, 693-705 (2018).

62. Baron, B. M. et al. Potent indole- and quinoline-containing N-methyl-Daspartate antagonists acting at the strychnine-insensitive glycine binding site. J. Pharmacol. Exp. Ther. 262, 947-956 (1992).

\section{Acknowledgements}

This work was supported by the French government (Investissements d'Avenir ANR-10LABX-54 MEMO LIFE and ANR-11-IDEX-0001-02 PSL $^{\star}$ Research University), Agence Nationale de la Recherche (ANR grant GluBrain3A to M.A.D. and P.P.), and the European Research Council (ERC Advanced Grant \#693021 to P.P.). We thank Nobuki Nakanishi and Stuart Lipton (Scintillon Institute, San Diego, CA, USA) for providing the GluN3A-KO mouse line. We also thank Boris Barbour and Mariano Casado for critical reading of the manuscript.

\section{Author contributions}

T.G., M.A.D., and P.P. designed the project. T.G. performed all the experiments on recombinant receptors and S.A.G. performed the experiments on hippocampal slices. M. D. provided technical support in molecular biology and cell culture. T.G., S.A.G., and P. P. analyzed the data, and T.G., M.A.D., and P.P. wrote the manuscript. M.A.D. and P.P supervised the project.

\section{Additional information}

Supplementary Information accompanies this paper at https://doi.org/10.1038/s41467 018-07236-4.

Competing interests: The authors declare no competing interests.

Reprints and permission information is available online at http://npg.nature.com/ reprintsandpermissions/

Publisher's note: Springer Nature remains neutral with regard to jurisdictional claims in published maps and institutional affiliations.

\footnotetext{
Open Access This article is licensed under a Creative Commons AY Attribution 4.0 International License, which permits use, sharing,
adaptation, distribution and reproduction in any medium or format, as long as you give appropriate credit to the original author(s) and the source, provide a link to the Creative Commons license, and indicate if changes were made. The images or other third party material in this article are included in the article's Creative Commons license, unless indicated otherwise in a credit line to the material. If material is not included in the article's Creative Commons license and your intended use is not permitted by statutory regulation or exceeds the permitted use, you will need to obtain permission directly from the copyright holder. To view a copy of this license, visit http://creativecommons.org/ licenses/by/4.0/.
}

(c) The Author(s) 2018 